\title{
High-Resolution Electrical Stimulation of Primate Retina for Epiretinal Implant Design
}

\author{
Chris Sekirnjak, ${ }^{1}$ Pawel Hottowy, ${ }^{2}$ Alexander Sher ${ }^{2}$ Wladyslaw Dabrowski, ${ }^{3}$ Alan M. Litke, ${ }^{2}$ and E. J. Chichilnisky ${ }^{1}$ \\ ${ }^{1}$ Systems Neurobiology Laboratory, The Salk Institute for Biological Studies, San Diego, California 92037, ${ }^{2}$ Santa Cruz Institute for Particle Physics, \\ University of California, Santa Cruz, California 95064, and ${ }^{3}$ Faculty of Physics and Applied Computer Science, AGH University of Science and Technology, \\ 23 30-059, Krakow, Poland
}

The development of retinal implants for the blind depends crucially on understanding how neurons in the retina respond to electrical stimulation. This study used multielectrode arrays to stimulate ganglion cells in the peripheral macaque retina, which is very similar to the human retina. Analysis was restricted to parasol cells, which form one of the major high-resolution visual pathways in primates. Individual cells were characterized using visual stimuli, and subsequently targeted for electrical stimulation using electrodes $9-15 \mu \mathrm{m}$ in diameter. Results were accumulated across $16 \mathrm{ON}$ and 9 OFF parasol cells. At threshold, all cells responded to biphasic electrical pulses $0.05-0.1 \mathrm{~ms}$ in duration by firing a single spike with latency lower than $0.35 \mathrm{~ms}$. The average threshold charge density was $0.050 \pm 0.005$ $\mathrm{mC} / \mathrm{cm}^{2}$, significantly below established safety limits for platinum electrodes. ON and OFF ganglion cells were stimulated with similar efficacy. Repetitive stimulation elicited spikes within a $0.1 \mathrm{~ms}$ time window, indicating that the high temporal precision necessary for spike-by-spike stimulation can be achieved in primate retina. Spatial analysis of observed thresholds suggests that electrical activation occurred near the axon hillock, and that dendrites contributed little. Finally, stimulation of a single parasol cell produced little or no activation of other cells in the $\mathrm{ON}$ and OFF parasol cell mosaics. The low-threshold, temporally precise, and spatially specific responses hold promise for the application of high-density arrays of small electrodes in epiretinal implants.

Key words: prosthetic; threshold; precision; evoked; macaque; receptive field; retina; visual

\section{Introduction}

In 1755, Charles LeRoy produced visual sensations of light by passing an electrical charge through the eye of a blind man (LeRoy, 1755). Since then, the idea of restoring vision in retinas with severe neurodegenerative diseases has moved from distant dream to near-future reality. Damaged photoreceptors can be bypassed by electrically stimulating the surviving inner retinal neurons through a device implanted on the retinal surface. The development of such retinal prosthetics has progressed steadily during the past decade (Zrenner, 2002; Loewenstein et al., 2004; Veraart et al., 2004; Weiland et al., 2005; Javaheri et al., 2006): long-term low-resolution implants in human patients have recently been shown to restore rudimentary perception of light and simple pattern recognition (Yanai et al., 2007).

However, our understanding of neuronal activation in the retina by applying extracellular electric stimuli is incomplete. Lit-

\footnotetext{
Received Nov. 19, 2007; revised March 19, 2008; accepted March 21, 2008.

This work was supported by the Salk Institute Pioneer Postdoctoral Fellowship, Second Sight Medical Products (SSMP), National Eye Institute Grants EY018003 (E.J.C.) and EY012893 (through SSMP), National Science Foundation Award PHY-0417175 (A.M.L.), and Burroughs Wellcome Fund Career Award at Scientific Interfaces (A.S.). We thank Martin Greschner for his help with the calculation of electrical images, Clare Hulse for her valuable assistance throughout each experiment, and Matt McMahon for his constructive comments on this manuscript.

C.S. provides consulting services to Second Sight Medical Products (Sylmar, CA). The other authors declare no competing financial interests.

Correspondence should be addressed to E. J. Chichilnisky, The Salk Institute for Biological Studies, 10010 North Torrey Pines Road, La Jolla, CA 92037. E-mail: ej@salk.edu.

DOI:10.1523/JNEUROSCI.5138-07.2008

Copyright $\odot 2008$ Society for Neuroscience $\quad$ 0270-6474/08/264446-11\$15.00/0
}

the is known about the cellular response properties of individual neurons, the differences between neuronal classes, or what portion of the cell is stimulated. Furthermore, it is unknown whether a high spatial resolution can be achieved with retinal implants by varying the size, number, and spacing of stimulation sites. To achieve near-normal vision, the diameter and density of stimulation electrodes will need to approach the size and density of the cells they are designed to stimulate. Testing in patients is currently limited to electrodes a few hundred micrometers in diameter (Humayun, 2003; Mahadevappa et al., 2005), but prototype arrays with much smaller electrodes placed in close proximity to the ganglion cell layer have been developed (Rizzo et al., 1996; Grumet et al., 2000; Stett et al., 2000; Litke et al., 2003; Wilms et al., 2003; Shah et al., 2007). These densely spaced arrays feature 10-40 $\mu \mathrm{m}$ electrodes and have traditionally been tested using rodent, rabbit, or chicken retinas. Although these array designs are likely to be used in the next generation of implantable devices, little is currently known about how they will interact with neurons in the human visual system.

Therefore, detailed knowledge of how individual neurons respond to electrical stimulation on a cellular level is needed for significant progress in the development of high-resolution implants.

In addition, successful prosthetic design relies on several important factors. First, the strength of electrical stimulation must remain within safety limits. Second, responses to fine temporal stimulation patterns must reproduce the normal timing preci- 
sion of retinal signals (Uzzell and Chichilnisky, 2004). Third, the size and spacing of stimulation electrodes must be functional in human retina. Finally, the spatial specificity of stimulation must be established and incorporated into implant design.

To approach these issues, the macaque monkey retina is the experimental model of choice, because it closely resembles the human retina (Rodieck, 1998). Several ganglion cell types have been identified and characterized anatomically and physiologically in the macaque, making it possible to examine the effects of stimulation on specific cell types with known projections in the brain. The present work focuses on ON and OFF parasol cells, which together constitute the second most dense visual pathway in the primate retina (Rodieck, 1998; Dacey, 2004) and form the dominant projection to the magnocellular layers of the lateral geniculate nucleus (Van Essen, 1985; Merigan and Maunsell, 1993). Parasol cells are thought to participate in behaviorally significant functions such as high-resolution vision and motion sensing (Rodieck, 1998) and thus comprise an important target for prosthetic stimulation. In the past, studies of electrical stimulation in nonhuman primates have been limited to measurements of intraretinal axon conduction velocity (Fukuda et al., 1988), response latencies to optic chiasm stimulation (Dreher et al., 1976), and computational modeling (Eckmiller et al., 2005). We reported in a previous study that macaque ganglion cells can respond to direct electrical stimulation (Sekirnjak et al., 2006); however, no detailed measurements of threshold, spike latency and precision, or spatial selectivity were provided.

This study presents the first detailed analysis of direct electrical stimulation of identified ganglion cells in peripheral primate retina. The results demonstrate that implants with low stimulation currents and high spatial and temporal resolution are feasible in humans.

\section{Materials and Methods}

Retinal preparation. Four male rhesus monkeys (Macaca mulatta) were used in this study. Before enucleation, animals were deeply and terminally anesthetized by other experimenters in accordance with institutional guidelines for the care and use of animals. Immediately after enucleation, the anterior portion of the eye and vitreous were removed in room light and the eye cup was placed in a bicarbonate-buffered Ames' solution (Sigma, St. Louis, MO). The tissue was stored in darkness at $32-34^{\circ} \mathrm{C}, \mathrm{pH} 7.4$, before dissection.

Under infrared illumination, pieces of peripheral retina $1-2 \mathrm{~mm}$ in diameter (eccentricity, $8-11 \mathrm{~mm}$ ) were isolated from the retinal pigment epithelium and placed flat against a planar array of 61 microelectrodes, with the ganglion cell layer facing the array. A transparent membrane was positioned over the tissue to exert gentle pressure on the preparation. The assembly was then mounted on a circuit board attached to an inverted microscope and continuously superfused with Ames' solution bubbled with $95 \%$ oxygen and $5 \%$ carbon dioxide at a flow rate of 2-4 $\mathrm{ml} / \mathrm{min}$ (chamber volume $0.4 \mathrm{ml}$ ) and maintained at $30-33^{\circ} \mathrm{C}$.

Multielectrode array. The array has been described in detail previously (Litke, 1998; Litke et al., 2003; Sekirnjak et al., 2006). Briefly, it consisted of a hexagonal arrangement of 61 extracellular electrodes, used both to record action potentials from ganglion cells and to inject current into the tissue. Each electrode was formed by microwells, which were electroplated with platinum before an experiment. Electrode diameter varied between 9 and $15 \mu \mathrm{m}$, with a fixed interelectrode spacing of $60 \mu \mathrm{m}$. The planar electrode area $\left(\pi r^{2}\right)$ was used to calculate charge densities. All stimulations were performed using a monopolar configuration (current flow from electrode to distant ground wire).

Electrical stimulation and recording. The stimulation pulse consisted of a cathodic (negative) current pulse of amplitude $A$ and duration $d$, followed immediately by an anodic (positive) pulse of amplitude $A / 2$ and duration $2 d$. All pulses were calibrated to produce stimuli with zero net charge to minimize electrode corrosion and tissue injury. Pulse durations in this study refer to the duration $d$ of the cathodic phase and current values refer to the cathodic phase amplitude $A$. In most cases, pulse duration was $0.05 \mathrm{~ms}$, and in several cases $0.1 \mathrm{~ms}$. Stimulation frequency was typically $5-10 \mathrm{~Hz}$. All electrical pulses were delivered in darkness.

For each cell, the electrode that recorded the largest spikes was designated as the "primary electrode." Most stimulation pulses were delivered through a neighboring electrode on the array, $60 \mu \mathrm{m}$ distant to the primary electrode. This approach significantly reduced the stimulus artifact and avoided amplifier saturation (Sekirnjak et al., 2006). In a few cells, stimulation at the primary electrode was attempted. This was limited to cases in which exceptionally large spikes could be detected on the stimulating electrode during the artifact, or in which a clearly isolated signal from the same cell could be recorded at a neighboring electrode.

Selection of the stimulation site was aided by a map of spike amplitudes surrounding each primary electrode. Because large signals presumably indicate closer proximity to the soma, stimulation was usually attempted using an adjacent electrode with a large spike amplitude.

In the four retinas studied, a total of $123 \mathrm{ON}$ cells and 75 OFF cells were identified. Several cells of the ON and OFF parasol type were targeted for electrical stimulation in each retina, with a success rate of $46 \pm 7 \%$. A cell was abandoned when stimulation attempts at several neighboring electrodes failed to reliably yield an unambiguous evoked spike. In most cases, unsuccessful stimulation could be attributed to a large stimulus artifact that precluded the identification of the evoked response in the submillisecond range. Cells with small spike amplitudes were particularly difficult to detect in the nearly saturated amplifier signal. Furthermore, cells located near the edge of the array often lacked a neighboring electrode with a large spike amplitude, which could have served as a lowthreshold stimulation site. Stimulation success rate improved with practice from $29 \%$ in the first primate retina to $57 \%$ in the final retina.

Stimulation was typically commenced by using the lowest available current setting and was then increased systematically if no response was seen. The increase in stimulus amplitude was halted when amplifier saturation and the shape of the stimulus artifact prevented the unambiguous detection of evoked responses, typically $>0.07-0.15 \mathrm{mC} / \mathrm{cm}^{2}$. Threshold was defined as the lowest current that produced a spike on $50 \%$ of stimulus pulses while stimulating at $5-10 \mathrm{~Hz}$. The exact threshold value was interpolated from several pulse strengths near threshold using the pooled data shown in Figure 2C. Assuming random fluctuations of the stimulation threshold, the threshold data in Figure $2 C$ were fit with a cumulative Gaussian (error function): $f(x)=c+a G(x b+d)$, with

$$
G(x)=\frac{2}{\sqrt{\pi}} \int_{0}^{x} e^{-t^{2}} d t
$$

The error function $G(x)$ ranges from -1 to +1 , the free parameter $a$ represents the half-maximum response rate, $b$ is the stimulus strength scaling, $c$ is the offset of the midpoint on the response rate axis, and $d$ is the offset of the midpoint on the stimulus strength axis.

Spontaneous spikes were readily distinguished from evoked spikes because they bore no temporal relationship to the stimulus pulse, whereas evoked spikes were locked to the stimulus onset.

All submillisecond spike responses were partially obscured by the stimulus artifact. To remove the artifact, several hundred pulses were applied around spike threshold. About half of the pulses evoked spikes whereas the remainder did not. Successes and failures were averaged and subtracted to cleanly reveal the evoked spike (see Fig. 2). This subtraction method was also used to analyze responses below and above threshold as long as a few traces without evoked spikes were available. A detailed description of this technique has been described previously (Sekirnjak et al., 2006).

Latency was defined as the time between the onset of a $50 \mu$ s pulse and the first unambiguous downward deflection of the voltage signal indicating the evoked spike (see Fig. 3). In cases in which artifact subtraction yielded distorted or truncated spikes (indicating amplifier saturation), signals from four to eight more distant electrodes (60-180 $\mu \mathrm{m}$ away) 
were used to align the spike waveforms and accurately determine spike latency at the primary electrode.

To quantify spike precision, histograms of spike latencies (number of spikes per histogram, $199 \pm 91$ ) were fitted with a function representing the impulse response of a sequence of low-pass filters, specifically

$$
f(t)=\alpha\left(\frac{t-t_{0}}{\tau}\right)^{n} e^{-n\left(\frac{t-t_{0}}{\tau}-1\right)} .
$$

The free parameters $t_{0}$ and $\alpha$, respectively, represent the latency and amplitude of the response, $\tau$ represents the time constant of the individual filters, and $n$ represents the number of filters. The full width at half maximum of the best fit curve was measured and reported.

Receptive field analysis. An optically reduced stimulus from a cathode ray tube computer display refreshing at $120 \mathrm{~Hz}$ was focused on the photoreceptor outer segments. The photopic intensity was controlled by neutral density filters in the light path. Spatiotemporal receptive fields were measured using a dynamic checkerboard (white noise) stimulus in which the intensity of each display phosphor was selected randomly and independently over space and time from a binary distribution. The pixel size was selected to accurately capture the spatial structure of macaque parasol cell receptive fields (Chichilnisky, 2001).

The voltage signal on each electrode during the white noise presentation was digitized at $20 \mathrm{kHz}$ and stored for off-line analysis. Details of the recording and spike-sorting methods have been given previously (Litke et al., 2003; Litke et al., 2004). To describe how the cell integrates visual inputs over space and time, the spike-triggered average (STA) stimulus was computed for each ganglion cell (see Fig. 1) (Chichilnisky, 2001). An elliptical two-dimensional Gaussian function was fit to the spatial profile. Receptive field diameter was defined as the diameter of a circle with the same area as the 1 SD boundary of the Gaussian center profile (Chichilnisky and Kalmar, 2002). White noise data were collected continuously during several 20-30 min data runs before and after electrical stimulation attempts.

Receptive field location did not always match the location of the array electrode recording the largest spikes. The variable pressure exerted by the transparent membrane likely caused horizontal displacements of the photoreceptor layer; this was typically observed as an expansion of the entire visual field. To compare results across retinas, a linear scaling factor (1.03-1.41) was applied to bring the centers of parasol cell receptive fields in register with the underlying electrodes on which they were recorded. All receptive field diameters reported here have been adjusted in this manner.

Care was taken to match electrically stimulated cells with cells identified from visual stimulation. Average waveforms of electrically and visually evoked spikes were compared on the primary electrode as well as on several neighboring electrodes to verify cell identity.

Electrical image. Data from visual stimulation runs were also used for the calculation of electrical images (Litke et al., 2004). The electrical image was calculated separately for each recorded neuron and provides an illustration of the spatial extent of electrical signals produced by the cell. An automated spike-sorting and neuron identification procedure (Litke et al., 2004) was used to detect lower amplitude signals on nearby electrodes arising from the same cell as recorded on the primary electrode. To calculate the image, the average spike amplitude on each electrode on the array was determined and normalized to the amplitude of the electrode recording the largest spike (by definition, the primary electrode). The shape of each voltage signal allowed for the distinction of axonal (triphasic signals), somatic (biphasic signals with large negativefirst deflections), dendritic (smaller signals with positive-first deflections), as well as somatodendritic spikes (for waveform examples, see Litke et al., 2004). Electrodes with axonal spikes along the expected axon path (see below) were excluded, leaving only somatic and dendritic spikes. The electrical image was generated by interpolating (nonlinear Delaunay triangulation) between electrodes and producing an isoamplitude plot, which typically showed the primary electrode in the center (see Fig. 1). An elliptical two-dimensional Gaussian function was fit to this plot and a boundary at $1 \mathrm{SD}$ was drawn. Electrical image diameter was defined as the diameter of a circle with the same area as this boundary. Cells located at the edge of the array (with primary electrodes on the array perimeter) provided insufficient amplitude data to accurately determine electrical image size and were excluded from the electrical image analysis.

Distance from the soma. The distance between the stimulating electrode and the soma was measured for each cell from the same set of visual stimulation data as above. The approximate soma position was triangulated by calculating a center-of-mass location from the spike amplitudes on each electrode. After excluding electrodes with spike amplitudes of $<10 \%$ of the primary electrode signal, the center-of-mass coordinates were calculated as follows:

$$
x_{C M}=\frac{\sum_{i} A_{i} x_{i}}{\sum_{i} A_{i}} y_{C M}=\frac{\sum_{i} A_{i} y_{i}}{\sum_{i} A_{i}},
$$

with $A_{\mathrm{i}}$ being the spike amplitude on electrode $i$ and $x_{\mathrm{i}}$ and $y_{\mathrm{i}}$ its coordinates on the array. The distance between this center-of-mass and the stimulating electrode was used as a soma proximity measure (see Fig. 4). Included in the analysis were several cells stimulated at the primary electrode, which had some of the smallest distances in the dataset. Note that these calculations assume a uniformly conductive medium between the electrodes and the soma, as well as equal sensitivity of all electrodes.

Axon path analysis and threshold map. The path of the axon was estimated by lining up all electrodes showing small triphasic signals (Litke et al., 2004). Within the same piece of retina, axons tended to run parallel to one another as expected based on their trajectory toward the optic disk. This fact was used to establish an average axon direction for each preparation by calculating the mean angle of several unambiguous axons $(n=$ $4-9$ ) in a given retina. The angle between the average axon direction and a line connecting the triangulated soma center and the stimulating electrode was then measured for each cell. To overlay stimulation sites from all cells in one plot, the position coordinates for each cell were rotated about the estimated soma center location so that each axon path pointed to the right (see Fig. 4).

An elliptical two-dimensional Gaussian function was fit to the stimulation position coordinates using $1 /$ threshold as a measure of sensitivity at each location. The center of this Gaussian fit indicates the estimated location of maximal sensitivity to electrical stimulation and was located to the right of the origin (soma center). An estimate of the error in the location of this point was obtained by resampling from the collection of recorded cells with replacement, and calculating the Gaussian center for each resampled data set. The resampled centers were located close to the original center of sensitivity, indicating that the observed right shift of the location of maximal sensitivity was statistically significant.

The position of maximum sensitivity was further verified by calculating a center of mass for a subset of stimulation positions with coordinate average in the origin $(x=0, y=0)$. The resulting center of mass was located to the right of the origin, similarly to the location obtained from the Gaussian fit.

Spatial specificity analysis. To analyze the spatial spread of a single stimulus pulse, artifact subtraction was performed on every parasol cell in both the ON- and OFF-cell mosaics using data from the same stimulation run. All cells $(n=6)$ were directly stimulated at the primary electrode and the pulse duration in all stimulations was $0.05 \mathrm{~ms}$. The number of applied pulses in this analysis was $130 \pm 8$. Response rates were calculated by counting all spikes from a given cell in a $2 \mathrm{~ms}$ window after stimulation onset, divided by the total number of stimulation pulses. Several cells were spontaneously active but fired no spikes in the 2 ms counting window. The response rate of these cells was $<1 \%$ and they were labeled " $<1$ " in Figure 6 to convey that the cell was capable of spiking at the time the stimulation was performed. The stimulation charge in the six cells analyzed was $44 \pm 3 \mathrm{pC}$ and the stimulation charge density $0.037 \pm 0.007 \mathrm{mC} / \mathrm{cm}^{2}$, which was at or above threshold (118 \pm $8 \%$ of threshold).

Data processing and reporting. Multielectrode data were analyzed offline using Labview and Igor Pro. Means and SEs were calculated in Excel; the statistical tests were performed in Igor Pro. Images were processed in 
Photoshop and Intaglio. Statistical significance was calculated by performing a two-tailed twosample Wilcoxon-Mann-Whitney test with a significance limit of $p<0.05$. All reported error values are SEs of the mean.

\section{Results}

This study reports on the responses of 25 macaque retinal ganglion cells to electrical stimulation. Each cell was first identified and characterized using visual stimuli, then tested with electrical stimulation.

\section{Cell-type identification}

Retinal ganglion cells were classified on the basis of their responses to white noise stimulation (Chichilnisky and Kalmar, 2002). The visual stimulus consisted of a square lattice of randomly flickering pixels. Receptive fields were identified using reverse correlation with this stimulus. Cells were segregated into distinct classes according to their receptive field characteristics; ON and OFF parasol cells were classified by receptive field size, response kinetics, and tiling (Chichilnisky and Kalmar, 2002).

Of the 25 visually and electrically stimulated ganglion cells reported in this study, 16 were ON parasol cells and 9 OFF parasol cells. Figure $1 \mathrm{~A}$ shows the receptive field of an ON and an OFF cell and the array electrodes on which spikes from these cells were recorded ("primary" electrodes). The time course of the red, green, and blue spiketriggered stimulus is shown in Figure $1 B$. The cells were classified as ON or OFF based

Figure 1. White noise visual stimulation. $\boldsymbol{A}$, The average stimulus observed $50 \mathrm{~ms}$ before a spike in two primate retinal ganglion cells in one retina. Dots represent the location of each electrode in the 61-electrode array. The primary (recording) electrode is marked with a circle, the site of electrical stimulation with a radiating symbol. Lighter-than-background pixels describe the receptive field of an $0 \mathrm{~N}$ parasol cell (left), whereas the region of darker pixels indicates the receptive field of an OFF parasol cell (right). Scale bar, $65 \mu \mathrm{m}$. $\boldsymbol{B}$, Average time course of STA (spike-triggered average) contrast of the red, green, and blue display phosphors in the 300 ms preceding a spike, summed over several pixels in the center of the receptive field (same cells as in $\boldsymbol{A}$ ). Black dashed line shows the best-fit curve to the green signal (Chichilnisky and Kalmar, 2002). The ON cell (left) shows a dominant positive lobe whereas the OFF cell (right) exhibits a dominant negative peak. C, Receptive fields of nine $0 \mathrm{~N}$ parasol ganglion cells and $130 \mathrm{FF}$ parasol ganglion cells recorded simultaneously in this retina. Ellipses represent 1 SD of the Gaussian fit to the spatial profile of each receptive field. The shaded fields indicate cells electrically stimulated in this retina. The small circles mark the cells shown in the above panels (same scale as in $\boldsymbol{A}$ ). $\boldsymbol{D}$, Electrical images of two $0 \mathrm{~N}$ and two OFF cells in this retina. Colored lines represent the interpolated amplitudes of the electrical signal measured at all nearby electrodes, normalized to the largest spike signal. Black ellipses are 1SD of the Gaussian fits to the amplitude data and were used to describe the electrical image size of each cell (same scale as in $\boldsymbol{A}$ ).
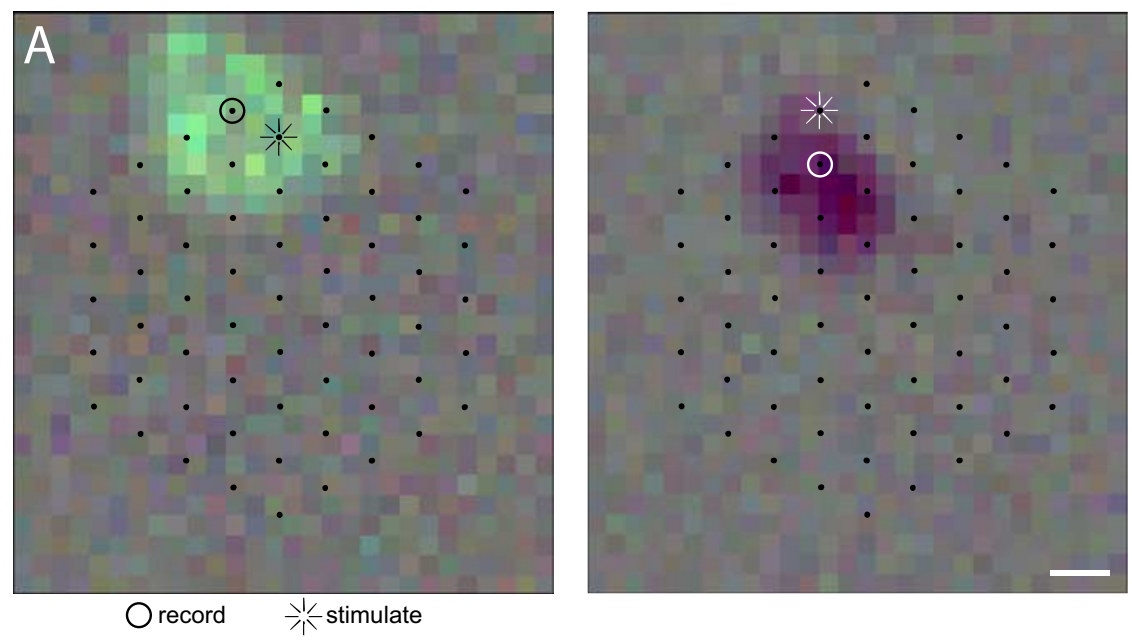

B
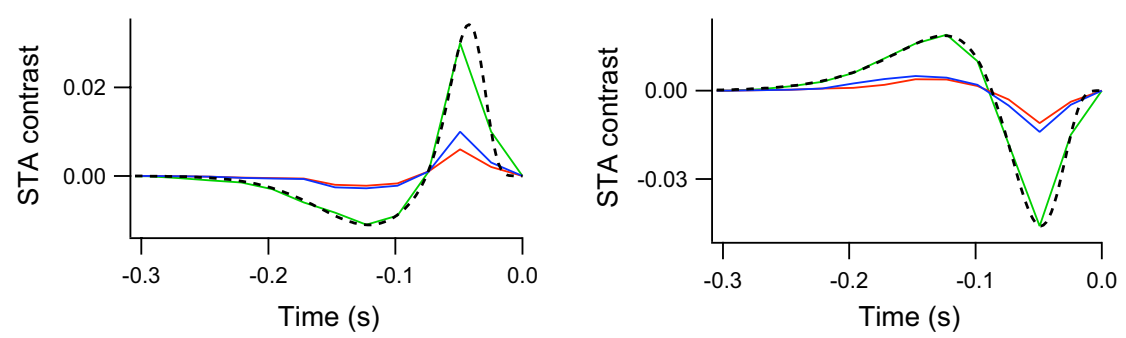

\section{C}

ON parasol cells

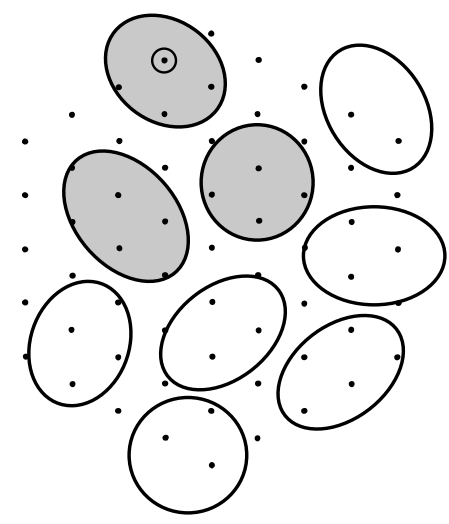

D

\section{ON parasol cells}

OFF parasol cells
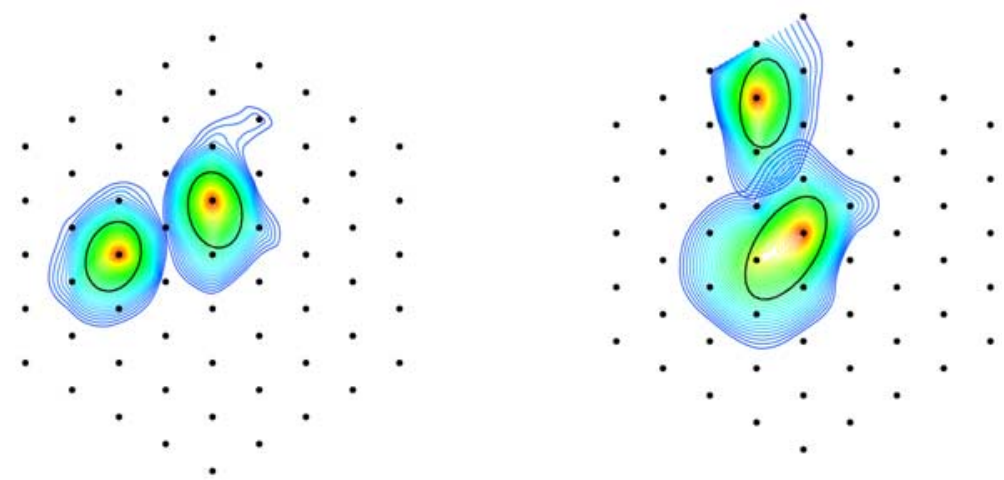
Table 1. Summary of visual and electrical stimulation results for $\mathrm{ON}$ and $\mathrm{OFF}$ parasol cells

\begin{tabular}{|c|c|c|c|c|c|c|c|c|c|c|c|}
\hline & & & & & Visual stimulati & & Electrical stimul & tion & & & \\
\hline & $n$ & $\begin{array}{l}\text { Retinal } \\
\text { eccentricity } \\
(\mathrm{mm})\end{array}$ & $\begin{array}{l}\text { Spike } \\
\text { amplitude } \\
(\mu \mathrm{V})\end{array}$ & $\begin{array}{l}\text { Electrical } \\
\text { image } \\
\text { diameter }(\mu \mathrm{m})\end{array}$ & $\begin{array}{l}\text { Receptive field } \\
\text { diameter }(\mu \mathrm{m})\end{array}$ & $\begin{array}{l}\text { Time of STA } \\
\text { peak (ms) }\end{array}$ & $\begin{array}{l}\text { Stim. electrode } \\
\text { diameter }(\mu \mathrm{m})\end{array}$ & $\begin{array}{l}\text { Stim. electrode } \\
\text { distance to soma }(\mu \mathrm{m})\end{array}$ & $\begin{array}{l}\text { Threshold } \\
\text { charge }(\mathrm{pC})\end{array}$ & $\begin{array}{l}\text { Threshold charge } \\
\text { density }\left(\mathrm{mC} / \mathrm{cm}^{2}\right)\end{array}$ & Latency (ms) \\
\hline ON parasol & 16 & $9.1 \pm 0.3$ & $422 \pm 51$ & $84.4 \pm 4.1$ & $109.0 \pm 4.5$ & $40.2 \pm 0.9$ & $13.5 \pm 0.5$ & $48.8 \pm 5.0$ & $59.0 \pm 5.7$ & $0.044 \pm 0.005$ & $0.18 \pm 0.01$ \\
\hline OFF parasol & 9 & $9.8 \pm 0.4$ & $298 \pm 34$ & $90.7 \pm 4.6$ & $99.5 \pm 4.6$ & $45.6 \pm 0.8$ & $12.9 \pm 0.8$ & $54.7 \pm 8.0$ & $73.4 \pm 5.5$ & $0.062 \pm 0.008$ & $0.19 \pm 0.02$ \\
\hline$p$ value & & 0.13 & 0.14 & 0.56 & 0.32 & 0.001 & 0.71 & 0.84 & 0.10 & 0.08 & 0.88 \\
\hline
\end{tabular}

Most parameters refer to values discussed in Materials and Methods and Results. Retinal eccentricity is the estimated distance from the fovea. Electrical image size is presumed to correspond to the somatodendritic extent of the cell. Time of STA peak refers to the time between the peak and the occurrence of a spike and is equivalent to the latency of light-evoked responses. All electrical stimulation results are obtained by stimulating with an electrode adjacent to the primary electrode. $p$ values are from a Wilcoxon-Mann-Whitney test (bottom row). Stim., Stimulation.

on the dominant positive or negative lobe of the response time course, respectively (Chichilnisky and Kalmar, 2002). Both cells belonged to a mosaic of cells that tiled the area over the array (Fig. $1 C)$. This mosaic tiling confirmed the identification of these cells as a single cell type. Previous work shows that these are parasol cells (Chichilnisky and Kalmar, 2002).

In addition to the receptive field, an electrical image was also generated for each cell during white noise stimulation. The electrical image reveals the spread of the average electrical signal generated by a spike around each primary electrode, and is displayed as a contour map of interpolated spike amplitudes (see Materials and Methods). Most signals at a distance from the primary electrode are presumably of dendritic origin and reflect the passive propagation of the somatic spike into the dendrites. Thus, the electrical image estimates somatodendritic extent for each parasol cell. Figure $1 D$ illustrates electrical images for several ON and OFF parasol cells in the same retina.

Table 1 presents a summary of the visual response properties of $\mathrm{ON}$ and OFF parasol cells, which were consistent with previous studies. ON cells showed a significantly shorter time to peak in the STA time course than OFF parasol cells (Chichilnisky and Kalmar, 2002). ON parasol cell receptive fields were $46 \pm 9 \%$ larger than those of OFF parasol cells within each recording (data not shown). Receptive field diameters of both ON and OFF parasol cells were systematically larger at higher eccentricities $\left(R^{2}=\right.$ 0.70 and 0.80 , respectively).

\section{Electrical stimulation thresholds and temporal precision}

Near threshold, primate parasol cells responded to an electrical stimulus pulse with a single evoked spike at submillisecond latency. An example is given in Figure $2 A$, which shows electrically evoked spikes for the same $\mathrm{ON}$ cell as in Figure $1 A-C$. The stimulation site was the electrode to the lower right of the primary electrode (Fig. 1A, symbols). Several pulses during this nearthreshold stimulation evoked spikes (successes), whereas others resulted in no spikes (failures). The large stimulation artifact was eliminated by averaging and subtracting failures from successes (see Materials and Methods) to reveal the waveform of the evoked spike (Fig. 2B). Note that the evoked submillisecond spike is the only response within the $8 \mathrm{~ms}$ time window shown. Longer-latency spikes and multiple-spike responses were not observed in the $20 \mathrm{~ms}$ time window following the first evoked spike. This observation held in all cells tested ( 24 cells) and when electrical stimulation strength was increased beyond threshold until virtually every pulse evoked a spike (three of three cells).

Figure $2 C$ shows the response rate of several cells over a wide range of stimulus strengths. The data follow a symmetrical sigmoidal shape. Stimulation threshold was defined for each cell as the stimulus strength necessary to evoke a spike on $50 \%$ of pulses delivered. The average threshold charge density across 25 cells
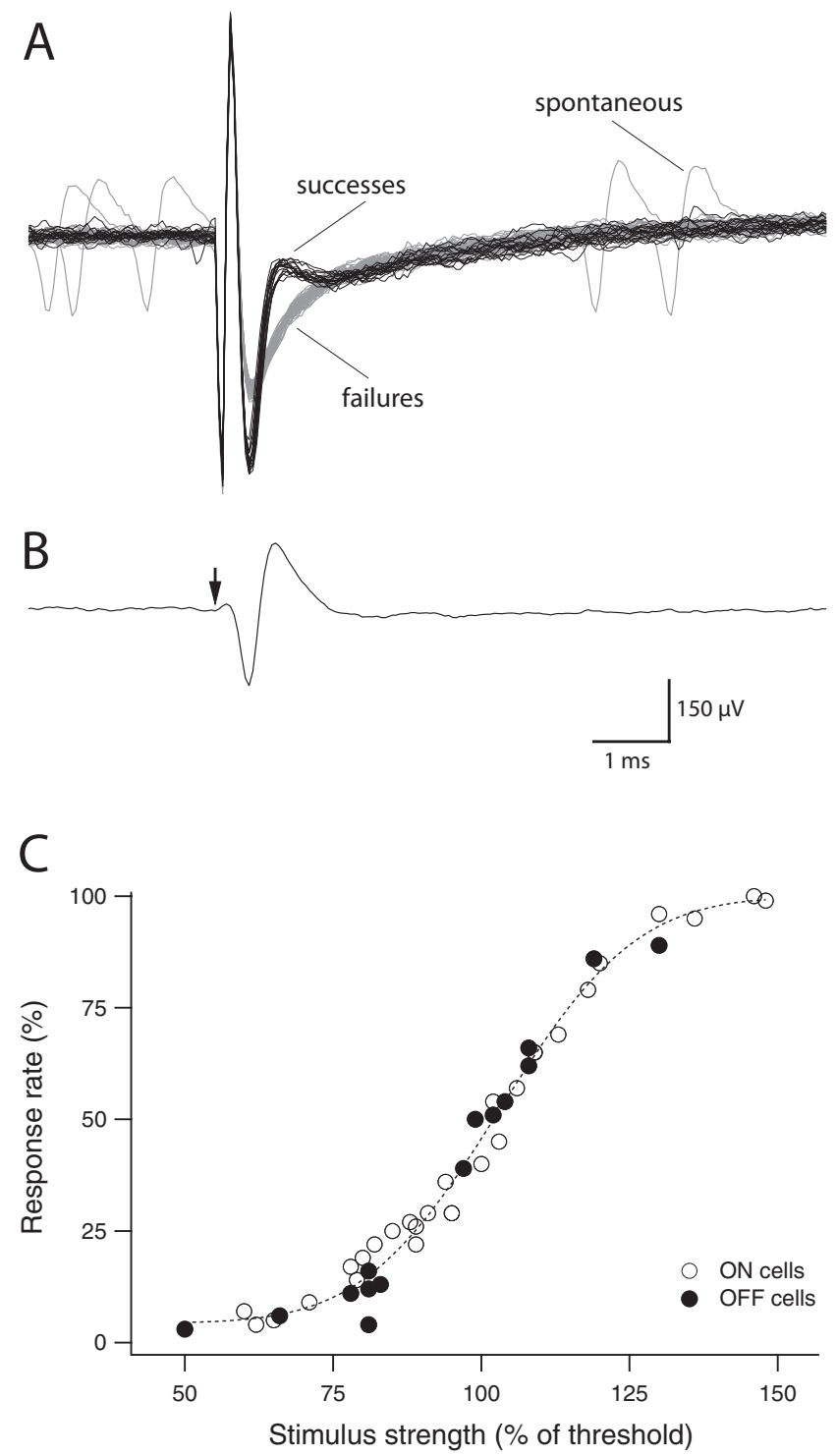

Figure 2. Spike responses to electrical stimulation. $\boldsymbol{A}$, Spikes recorded in the same $0 \mathrm{~N}$ cell shown in Figure $1 A$, stimulated using a neighboring electrode. A superposition of responses to 65 repeated pulses of $50 \mu$ s duration is shown. Near threshold, the electrical stimulus (large artifact) evoked either successful spikes (black traces) or no spikes (gray traces). Occasional spontaneous spikes also occurred before and after the stimulation. $\boldsymbol{B}$, The average evoked spike, obtained by subtracting failures from successes in $\boldsymbol{A}$. The evoked spike resembles the spontaneous spikes in $\boldsymbol{A}$. The arrow points to the onset of the stimulation pulse. $\boldsymbol{C}$, Response rate (fraction of pulses that evoked a spike) as a function of stimulus strength. Threshold was defined as a $50 \%$ response rate. Data from 18 parasol cells were pooled for this plot; open and closed symbols denote $\mathrm{ON}$ and $\mathrm{OFF}$ cells, respectively. The dashed line is an error function fit to the data (see Materials and Methods). 
was $0.050 \pm 0.005 \mathrm{mC} / \mathrm{cm}^{2}$, and the average threshold charge was $64 \pm 4 \mathrm{pC}$. The lowest threshold found was $0.018 \mathrm{mC} / \mathrm{cm}^{2}$ and the highest was $0.099 \mathrm{mC} / \mathrm{cm}^{2}$.

Thresholds are reported separately for ON and OFF parasol cells in Table 1. A weak trend toward higher threshold charge and charge density was observed in ON cells, but no statistically significant difference was observed. For example, in one retina, a single electrode recorded spikes from two nearby cells, an ON and an OFF parasol cell. When electrically stimulated, the ON cell showed a threshold charge of $60 \mathrm{pC}$, while the OFF cell had a threshold of $59 \mathrm{pC}$.

Four of these cells were also stimulated using the primary electrode (data not shown), which was always the closest electrode to the soma of the recorded cell. Because this arrangement greatly increased the stimulus artifact, the evoked spike responses were typically detected and recorded at a neighboring electrode. The threshold charge densities in this configuration decreased to $53 \pm 9 \%$ of the value measured when the stimulation site was an adjacent electrode (60 $\mu \mathrm{m}$ distant). Furthermore, seven additional cells were stimulated only at the primary electrode and yielded a threshold of $0.034 \pm 0.004 \mathrm{mC} / \mathrm{cm}^{2}$. These reductions in threshold are presumably attributable to the closer proximity between electrode and ganglion cell soma (see below).

Cells responded at submillisecond latencies. The average latency for all 25 cells was $0.19 \pm 0.01 \mathrm{~ms}$ when stimulated with $0.05 \mathrm{~ms}$ pulses. Table 1 shows the measured latencies in $\mathrm{ON}$ and OFF cells; both cell groups responded at similar times.

The evoked spikes occurred with high temporal precision. Figure 3 shows responses to $>200$ pulses near threshold and a histogram of the spike times. The responses had latencies of $\sim 0.2 \mathrm{~ms}$ and showed low latency variability: the majority of spikes were observed in the time window between 0.15 and $0.22 \mathrm{~ms}$, within $<0.1 \mathrm{~ms}$ of each other. The dotted line in Figure $3 A$ is a fit to the data (see Materials and Methods) with a width at half-maximum of $61 \mu$ s. Similar results were observed in all nine cells analyzed: Figure $3 B$ shows fits similar to the one in Figure $3 A$ for six ON and three OFF cells; the average width at half-maximum was $55 \pm 4 \mu$ s.

\section{Dependence of thresholds on stimulus location}

The location of the stimulation electrode relative to the target cell is expected to affect the threshold to electrical stimulation. Figure $4 \mathrm{~A}$ shows the threshold charge plotted against the squared distance between the stimulation electrode and the estimated location of the cell soma. The soma location was triangulated based on the spike amplitude on several electrodes (see Materials and Methods). Figure 4 includes several additional cells that were only stimulated directly at the primary electrode. The dashed line is a linear fit to the data and corresponds to an inverse square sensitivity to electrical stimulation $\left(R^{2}=0.58\right)$ (Jensen et al., 2003).

To visualize the dependence of thresholds on stimulation location in two dimensions, a map of stimulation sites, soma centers, and axon directions was produced. To present all cells in a uniform orientation, an approximate axon path direction was determined for each retina (see Materials and Methods). Figure $4 B$ shows location data from all electrically stimulated cells aligned at their soma centers (filled square). The view was rotated for each cell so that the direction of the axon path points to the right (dashed arrow). Each circle represents a stimulation electrode site and the circle diameter reflects the threshold charge. The lowest thresholds (smallest circles) were found to the right of the soma center, while the farthest stimulation sites produced the
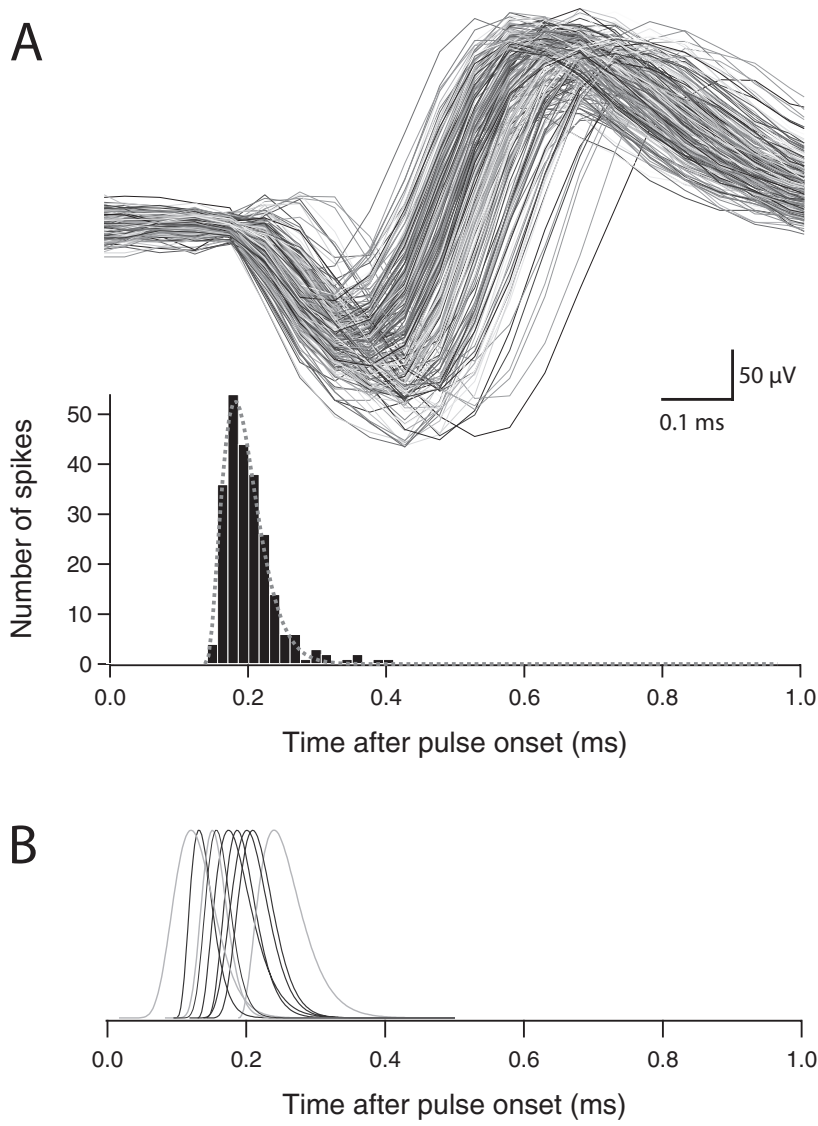

Figure 3. Precision of submillisecond latency responses to electrical stimulation. $\boldsymbol{A}$, Top, Superposition of responses of a primate retinal ganglion cell to 244 stimulus pulses delivered at $5 \mathrm{~Hz}$ near threshold (pulse duration, $0.05 \mathrm{~ms}$ ). The stimulation artifact has been subtracted as shown in Figure 2. Bottom, Latencies of each spike shown in $A$. Bin size, $15 \mu \mathrm{s}$. The dotted gray line is a fit to the data. $\boldsymbol{B}$, Normalized latency histograms of nine ganglion cells such as the one shown in $\boldsymbol{A}$. Only the fit lines are shown. Black lines indicate ON cells; gray lines indicate OFF cells.

highest thresholds. The small filled circle marks the center of a Gaussian fit to these data, indicating that the estimated site of highest sensitivity to electrical stimulation was located toward the axon.

\section{Additional factors influencing electrical stimulation thresholds}

To test the relationship between sensitivity to visual inputs and sensitivity to electrical stimulation, Figure $5 A$ shows the threshold charge as a function of the size of the receptive field in each cell. ON and OFF cell thresholds covered a similar range, and thresholds did not vary systematically with receptive field size.

To test the influence of the dendritic extent on electrically evoked spikes, the electrical image of each cell (see Materials and Methods) was compared with two response parameters, in Figure $5, B$ and $C$. Because the main contribution to the electrical image stems from dendritic signals, this parameter can be used to investigate whether the dendritic tree dictates electrical responses. No correlation between threshold and electrical image size was found (Fig. 5B). However, the latency of evoked spikes declined with electrical image size (Fig. $5 C, R^{2}=0.43$ ), as did spike amplitude $\left(R^{2}=0.50\right.$; data not shown). No correlation was found between receptive field diameter and electrical image diameter $\left(R^{2}=0.01\right.$; data not shown). 
A

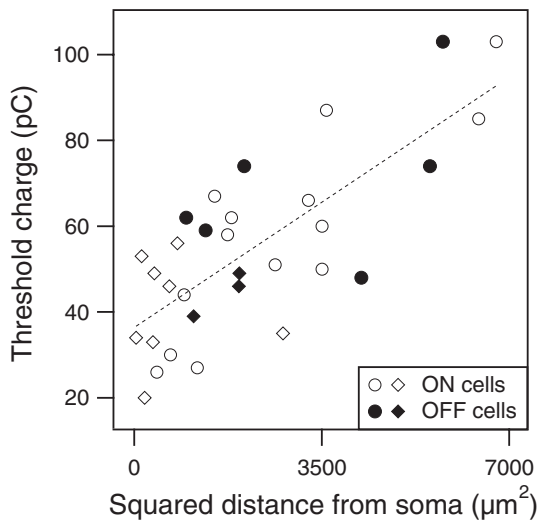

B

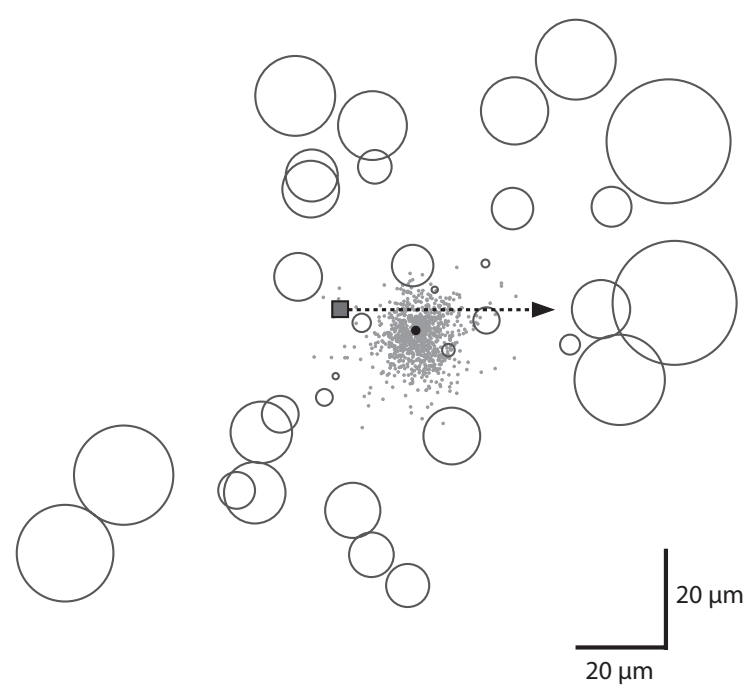

Figure 4. Sensitivity to spatial location of stimulation. $\boldsymbol{A}$, Threshold charge plotted against the square of the distance between stimulation electrode and estimated soma location. Most data are from stimulating at a neighboring electrode (circles), but several cells stimulated directly at the primary electrode were included (diamonds). The dashed line is a linear fit to the data $\left(R^{2}=0.58\right)$ and denotes a squared dependence of charge on distance from soma. $\boldsymbol{B}$, Stimulation sites (circles) plotted relative to the soma center (filled square). Data from all cells were aligned at the soma center and rotated so that the direction of the axon (dotted arrow) points to the right. Circle diameter is proportional to the threshold charge minus an offset (minimum 26 pC, maximum 103 pC). The lowest thresholds are found near the soma and the proximal portion of the axon. The filled circle indicates the center of a Gaussian fit to the data and the gray dots denote the expected error around this center (resampled 950 times with replacement; see Materials and Methods). This location of maximal sensitivity to electrical stimulation is situated $\sim 13 \mu \mathrm{m}$ to the right of the soma center.

\section{Spatial specificity of electrical stimulation}

The parasol cells stimulated in this study were organized in orderly mosaics tiling visual space (Fig. 1). To investigate whether stimulation of a single parasol cell also activated other parasol cells, the responses of nearby cells in the mosaic were analyzed. Figure 6 gives four examples of electrical stimulation targeted at different cells in two retinas, and the response rates of all other cells in both the ON and OFF parasol mosaics. Cells with bold receptive field outlines were stimulated near or above threshold using direct stimulation at the primary electrode. Dots mark all cells that were successfully stimulated in each retina using neighboring-electrode or at-soma stimulation. The data indicate that very few spikes were observed in cells that were not the target of stimulation. These spikes occurred at a rate consistent with spontaneous firing (data not shown). In the data of Figure 6, $\mathrm{A}$ and $D$, the targeted cell was entirely surrounded by neighbors in the mosaic, none of which responded to the electrical stimulus. Furthermore, the spatial specificity remained high when suprathreshold pulses were used: the stimulated cells in Figure 6, $B$ and $C$, responded with high probability, whereas none of the neighbors showed evoked responses. Six cells were analyzed in this manner with similar results.

\section{Discussion}

We used arrays of small, finely spaced electrodes to electrically stimulate two of the numerically dominant ganglion cell types in the primate retina: ON and OFF parasol cells. Parasol cells responded to electrical stimuli with charge levels well below safety limits. The response to electrical stimulation consisted of a single spike with short latency and high timing precision. Electrical stimulation could reliably elicit a spike in one parasol cell while not evoking spikes in any of the neighboring parasol cells. These results suggest that implants with relatively high temporal and spatial resolution are feasible in the human retina.

\section{Low stimulation thresholds}

Established electrochemical safety limits for platinum electrodes range from $0.1 \mathrm{mC} / \mathrm{cm}^{2}$ (Rose and Robblee, 1990) to 0.3-0.4 $\mathrm{mC} / \mathrm{cm}^{2}$ (Brummer and Turner, 1977). Primate parasol cells required very little current injection to elicit a spike $(0.050 \pm 0.005$ $\left.\mathrm{mC} / \mathrm{cm}^{2}\right)$. Threshold charge densities $<0.035 \mathrm{mC} / \mathrm{cm}^{2}$ were common, with the lowest at $\sim 0.020 \mathrm{mC} / \mathrm{cm}^{2}$ in several cells. When the electrode closest to the cell soma was used to deliver the pulses, thresholds dropped further by nearly half.

To compare thresholds in this study to results from other groups it is essential to distinguish between direct and indirect activation of ganglion cells. Several groups have targeted deeper retinal neurons (bipolar cells and photoreceptors) for epiretinal stimulation, which activates ganglion cells through the retinal neural network and thus stimulates them indirectly (Jensen and Rizzo, 2007). Such stimulation attempts use much larger electrodes $(125-500 \mu \mathrm{m})$ and/or long-duration stimulation pulses $(\sim 1 \mathrm{~ms})$, and result in multiple evoked spikes at long latencies $(\sim 10 \mathrm{~ms})$. With these stimulation configurations, spike thresholds are typically much higher than the direct-activation values reported in this study (Jensen et al., 2003; Suzuki et al., 2004; Guven et al., 2005; Jensen and Rizzo, 2007; Ye and Goo, 2007). Results from the present study are most comparable with recently published reports of epiretinal stimulation that activated ganglion cells directly by using small electrodes and short pulses: $0.05-0.31 \mathrm{mC} / \mathrm{cm}^{2}$ for $40 \mu \mathrm{m}$ disk electrodes in frog retina (Kuras et al., 2004), $0.14-0.25 \mathrm{mC} / \mathrm{cm}^{2}$ for $30 \mu \mathrm{m}$ cone-shaped electrodes in rabbit retina (Fried et al., 2006), and 0.02-0.20 mC/ $\mathrm{cm}^{2}$ for $8-12 \mu \mathrm{m}$ disk electrodes in rat retina (Sekirnjak et al., 2007). Thus, the thresholds for macaque parasol cells are comparable with those in other species, albeit in the lower end of the range. Because the present study focused on parasol cells, whereas other previous studies did not distinguish cell types, differences from those studies could primarily reflect differences between cell types.

\section{High temporal resolution}

The artifact subtraction method used for spike detection permitted observation of spikes as early as $0.12 \mathrm{~ms}$ after pulse onset. All electrically evoked spikes in this study occurred within $0.35 \mathrm{~ms}$ of 

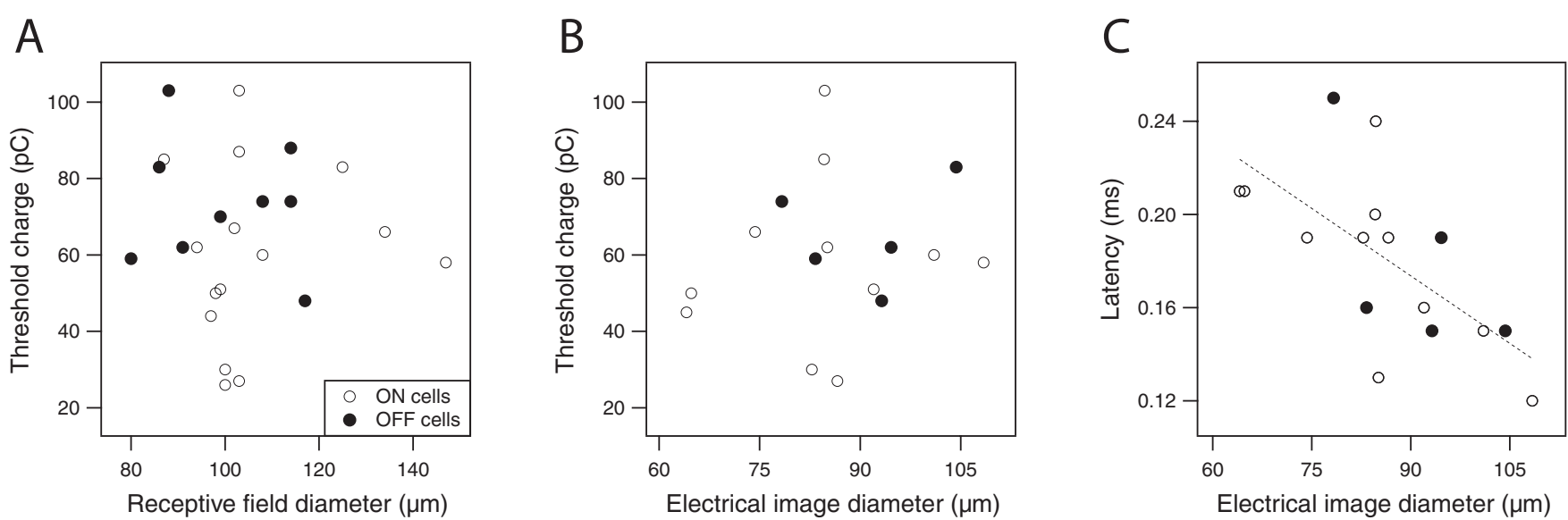

Figure 5. Relationship between stimulation parameters. $A$, Dependence of threshold charge on receptive field size. Open circles, $0 \mathrm{~N}$ cells; closed circles, 0 FF cells. No significant correlation was found $\left(R^{2}=0.001\right) \cdot B$, Dependence of threshold charge on electrical image size. No significant correlation was found $\left(R^{2}=0.03\right)$. Nine cells were omitted because their location near the edge of the array precluded the calculation of complete electrical images. $C$, Dependence of evoked spike latency on electrical image size. The dashed line is a linear fit $\left(R^{2}=0.43\right)$.

stimulus onset, the shortest latencies ever reported for mammalian retinal ganglion cells.

Several recent studies have reported short-latency spikes, followed by long-latency responses (Jensen et al., 2005; Fried et al., 2006; Sekirnjak et al., 2006). Long-latency spikes were not observed in this study: each pulse was followed by a single spike with submillisecond latency (Fig. 2). Several factors could contribute to this difference from previous reports. First, the small-diameter electrodes used in this study virtually guaranteed that ganglion cells were only activated directly. As stated above, long-latency spikes are associated with indirect stimulation by way of deeper retinal neurons, typically by using much larger electrodes. Second, the current required to elicit spikes in parasol cells was low; late spikes are typically observed when the current is significantly above threshold (Sekirnjak et al., 2006). Third, very short stimulation pulses were used (mostly $0.05 \mathrm{~ms}$ ); shorter pulse durations can abolish late phase spiking in rabbit ganglion cells (Fried et al., 2006). Fourth, primate ganglion cells may be less prone to firing doublets or bursts.

Response timing in primate parasol cells was remarkably reproducible. Each cell showed low latency jitter, as evidenced by narrow time histograms (Fig. 3B). Furthermore, the cells tested exhibited similar latencies at threshold: most cells responded within $0.1-0.2 \mathrm{~ms}$ after pulse onset. Much greater variability in latency has been reported in rodent retina (Sekirnjak et al., 2006). This difference is probably attributable to the fact that the rodent study, and all previous studies of electrical stimulation of ganglion cells, did not focus on a specific morphological cell type.

\section{Activation site for evoked spikes}

Information about potential cellular activation sites can be obtained from stimulation results relating to dendrites, the soma, and the axon.

\section{Dendrites}

Ganglion cells with larger dendritic fields may be expected to occupy a larger fraction of the electric field generated by the pulse. Thus, if dendrites contribute to evoked spike initiation, lower thresholds might be expected in cells with larger dendritic fields. No correlation was found between stimulation threshold and either electrical image size or receptive field size, two parameters, which presumably covary with dendritic field diameter. This suggests that dendritic field extent and stratification do not dictate the threshold of responses to extracellular current injection. However, the latency of evoked spikes declined systematically with electrical image size, suggesting that dendritic extent could contribute to response timing. Therefore, cell morphology can influence ganglion cell responses but more detailed studies are required to elucidate its role.

\section{Soma}

Threshold depended strongly on the location of the stimulation electrode relative to the soma. Thresholds increased with the square of the distance to the stimulation site, consistent with the inverse square decline of electrical field strength. A similar observation was made for monophasic stimulation of rabbit retinal ganglion cells (Jensen et al., 2003).

\section{Axon}

The lowest thresholds were found when the stimulation electrode was located in close proximity to both soma and axon. The estimated location of highest sensitivity to stimulation was $13 \mu \mathrm{m}$ from the soma along the path of the axon. This finding provides experimental support for the hypothesis that the site of activation during electrical stimulation is the axon hillock or the initial portion of the axon (Coombs et al., 1957; Wollner and Catterall, 1986; Fohlmeister and Miller, 1997; Schiefer and Grill, 2006; Sekirnjak et al., 2006).

\section{Shortcomings of the animal model}

This study used healthy primate retinal tissue as a model for applicability of retinal prostheses in blind humans. Several groups have reported that degenerated retinas show higher thresholds than intact retinas, as measured mostly with large (100-400 $\mu \mathrm{m}$ ) stimulation electrodes (Humayun et al., 1994; Katona et al., 1998; Rizzo et al., 2003; Suzuki et al., 2004). The long latencies in these studies indicate that they stimulated ganglion cells indirectly through the retinal neural network; currently no data for direct ganglion cell activation is available. In degenerating retinas, the loss of photoreceptors drastically affects bipolar and amacrine cells, as evidenced by massive remodeling, rewiring, and extensive neuronal migration (Jones and Marc, 2005). Ganglion cells, however, are less affected: reduction of total cell number by neuronal death has been reported, along with occasional formation of neurite fascicles containing ganglion cell dendrites, and rare eversion of somas to the distal retina 
A
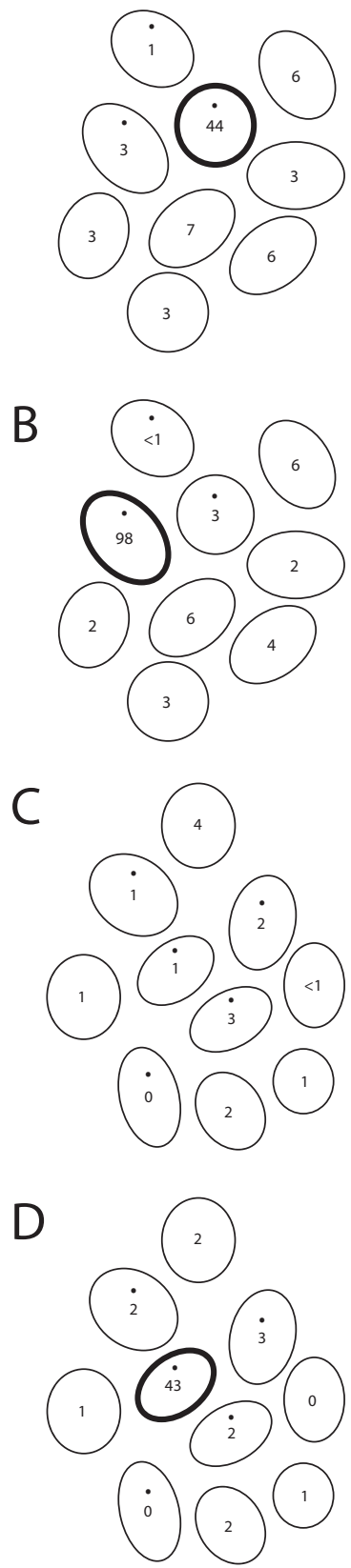

OFF parasol
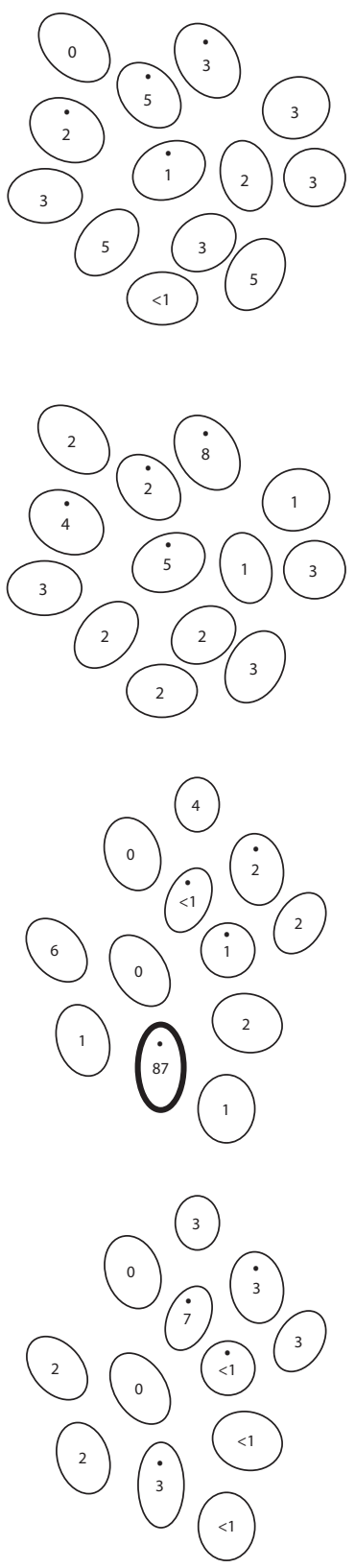

Figure 6. Spatial specificity. Receptive field outlines for ON and OFF parasol mosaics. Numbers denote response rates (in percent) to stimulation at the primary electrode (outlined in bold). Dots indicate cells that were stimulated in this retina. $A$ and $\boldsymbol{B}$ are from the same retina as shown in Figure 1. $\boldsymbol{C}$ and $\boldsymbol{D}$, are from a different retina. To emphasize that the vast majority of cells were definitely alive at the time of stimulation, spontaneous firing rates were not subtracted.

(Jones et al., 2003). It is possible that higher thresholds in diseased retinas reflect the remodeled outer retina or the lower ganglion cell density. Additional studies in degenerated retina will be required to ascertain whether individual surviving ganglion cells respond normally to electrical stimulation. Theoretically, epiretinal implants with small electrodes would be able to bypass much of the diseased retinal circuitry and drive ganglion cells directly.

The in vitro design of the present experiments largely mimics the situation in vivo, but several differences remain. By removing the sclera and epithelium from the retina, the current flow into the surrounding tissue is altered. Given the close apposition between tissue and array, such long-distance current spread may be of little concern, yet distortions in current flow patterns cannot be excluded. Furthermore, a thin layer of vitreous humor typically covers the retina in human patients (Sanders et al., 2007). Experiments that attempt to recreate this interposed material in vitro are warranted to determine its influence on ganglion cell thresholds and further validate the in vitro technique. Finally, the retina is spherical in vivo, whereas it has been flattened in the present experiments.

\section{Implications for retinal implants}

This study addresses several areas of improvement necessary for the development of a high-resolution retinal implant: the applicability to stimulation in the primate retina, low charge thresholds, the temporal precision of elicited responses, and the feasibility of fine-grained stimulation.

\section{Primate retina}

Macaque and human retinas resemble each other closely, and morphologically distinct cell types are clearly identifiable as homologous in the two species (Rodieck, 1998). Thus, the present findings imply that a high-resolution prosthesis that targets individual ganglion cells is likely to perform with similar efficacy, temporal precision, and spatial specificity in humans.

\section{Thresholds}

A goal of any implanted stimulator is to accomplish effective stimulation while injecting as little current as possible. Prevention of electrode degradation and tissue damage, low heat production, and power circuit requirements all mandate pulses with minimal charge density. The present results show that stimulation of primate ganglion cells is not only safe, but additionally affords a factor of 3-20 of flexibility to safely increase the injected current. This flexibility may be of use in a human implant to compensate for the distance between array and retina, improve the reliability of responses, use stimulation amplitude to code for perceptual brightness, or stimulate multiple cells at once.

\section{Tissue-electrode interface}

One factor that may contribute to the low observed thresholds was the close proximity of the electrode array to the retina. In the present work, thresholds were sensitive to the amount of pressure applied to the tissue, which presumably altered the proximity to the array (our unpublished observations). Future high-density retinal implants will require novel methods for positioning the array as close to retinal tissue as possible, and approaches to achieve this are currently under development (Johnson et al., 2004; Palanker et al., 2007). The relevance of the present results is dependent on advances in implant attachment and reliable positioning of the electrode close to the target cell; additional in vitro studies in this direction are therefore indicated.

In the present experiments, platinum was electroplated onto the electrodes, a process that can greatly increase the area of metal in contact with the solution (Mathieson et al., 2004). Thus, charge density values calculated using the geometric electrode area have been overestimated and true thresholds will be lower than reported, further lowering the likelihood of electrochemical electrode damage. Given the low thresholds, it appears that platinum should suffice for small electrode stimulation and a shift toward less widely used compounds (such as iridium oxide) may not be necessary. 


\section{Temporal resolution}

The present results have three major implications for the timing of responses to electrical stimulation. First, the observed submillisecond response latencies imply that the implant will introduce virtually no additional delay between stimulus and percept in a human patient. Second, because only one spike is elicited per pulse, trains of pulses can, in principle, reproduce any temporal pattern, including high-frequency firing (Fried et al., 2006). The absence of long-latency spikes eliminates the potential overlap of spikes during natural firing patterns. Third, the high temporal precision of evoked spikes is critical for driving an individual cell repetitively with a pulse pattern on a spike-by-spike basis. It also allows for the reproducible generation of synchronized activity in groups of ganglion cells. Millisecond spike-time precision has been reported in the retina of several species (Berry and Meister, 1998; Uzzell and Chichilnisky, 2004), suggesting that visual information may be transmitted to the brain in the exact times of individual spikes, rather than the firing rate averaged over tens or hundreds of milliseconds (but see Chichilnisky and Kalmar, 2003). In the human visual system, simultaneity in the millisecond and even submillisecond range provides a strong benefit during object recognition in partial shape cue experiments (Greene, 2006). Thus, the ability to accurately control the spike timing of individual ganglion cells may allow retinal prosthetics to apply the emerging understanding of the neural code to artificial vision (Von der Malsburg, 1994; Usrey and Reid, 1999).

\section{$O N$ and $O F F$ cells}

Within a given morphological class, ON and OFF cells differ in their retinal connectivity (Sterling and Demb, 2004), dendritic tree extent (Peichl et al., 1987), dendritic tree lamination (Sterling and Demb, 2004), and light-response properties (Chichilnisky and Kalmar, 2002). One might expect that these two cell types also show conspicuous differences in their response to extracellular stimulation. The present findings suggest that although ON parasol cells may have a tendency toward lower stimulation thresholds (Table 1), there is extensive overlap in the two cell populations (Fig. 5). Thus, both ON and OFF cells can be stimulated with small-diameter electrode arrays at comparable threshold levels. Similar findings have been reported previously in tiger salamander retina (Margalit and Thoreson, 2006). This absence of a striking threshold difference reduces the likelihood that one of the two visual pathways can be activated without the other simply by varying the stimulation current. It remains to be seen whether $\mathrm{ON}$ and OFF cells respond differently to variations in pulse duration, shape, or polarity. These considerations raise a more general question: how can the $\sim 20$ different ganglion cell types in primate retina be differentially activated to produce a natural visual signal in the optic nerve? A possible approach may include tunable retinal encoders that are trained in a learning process involving feedback from the human subject (Eckmiller, 1997). In this perception-based iterative tuning procedure, each cell will be stimulated as required to produce the desired visual percept. It is an open question whether such an approach will be practical for appropriately stimulating the many pathways that send visual signals to distinct targets in the brain.

\section{Spatial resolution}

Single-cell stimulation was specific to the targeted parasol cell, and all other nearby $\mathrm{ON}$ and OFF parasol cells were not activated. Given the low stimulation thresholds and minimal current spread, this specificity would be expected to also apply during simultaneous activation of neighboring electrodes on the array, at least within the parasol cell class. However, the possibility that summation of the electrical fields would recruit nonparasol cells in the vicinity of multiple active electrodes cannot be excluded without additional experiments.

Targeting individual ganglion cells with a high-resolution implant containing hundreds or thousands of electrodes is currently not feasible (Weiland et al., 2005). With technological advances in microelectronics, packaging, and implant attachment, it seems possible that the spatial resolution achieved here may soon be possible in vivo. Future studies will be needed to further examine the limits of spatial resolution in other cell types, including the high-density midget cells, as well as in the central retina.

\section{References}

Berry MJ, Meister M (1998) Refractoriness and neural precision. J Neurosci 18:2200-2211.

Brummer SB, Turner MJ (1977) Electrical stimulation with Pt electrodes: II-estimation of maximum surface redox (theoretical non-gassing) limits. IEEE Trans Biomed Eng 24:440-443.

Chichilnisky EJ (2001) A simple white noise analysis of neuronal light responses. Network 12:199-213.

Chichilnisky EJ, Kalmar RS (2002) Functional asymmetries in ON and OFF ganglion cells of primate retina. J Neurosci 22:2737-2747.

Chichilnisky EJ, Kalmar RS (2003) Temporal resolution of ensemble visual motion signals in primate retina. J Neurosci 23:6681-6689.

Coombs JS, Curtis DR, Eccles JC (1957) The interpretation of spike potentials of motoneurones. J Physiol (Lond) 139:198-231.

Dacey DM (2004) Origins of perception: retinal ganglion cell diversity and the creation of parallel visual pathways. In: The cognitive neurosciences (Gazzaniga MS, ed), pp 281-301. Cambridge, MA: MIT.

Dreher B, Fukada Y, Rodieck RW (1976) Identification, classification and anatomical segregation of cells with X-like and Y-like properties in the lateral geniculate nucleus of old-world primates. J Physiol (Lond) 258:433-452.

Eckmiller R (1997) Learning retina implants with epiretinal contacts. Ophthalmic Res 29:281-289.

Eckmiller R, Neumann D, Baruth O (2005) Tunable retina encoders for retina implants: why and how. J Neural Eng 2:S91-S104.

Fohlmeister JF, Miller RF (1997) Mechanisms by which cell geometry controls repetitive impulse firing in retinal ganglion cells. J Neurophysiol 78:1948-1964.

Fried SI, Hsueh HA, Werblin FS (2006) A method for generating precise temporal patterns of retinal spiking using prosthetic stimulation. J Neurophysiol 95:970-978.

Fukuda Y, Watanabe M, Wakakuwa K, Sawai H, Morigiwa K (1988) Intraretinal axons of ganglion cells in the Japanese monkey (Macaca fuscata): conduction velocity and diameter distribution. Neurosci Res $6: 53-71$.

Greene E (2006) Simultaneity in the millisecond range as a requirement for effective shape recognition. Behav Brain Funct 2:38.

Grumet AE, Wyatt Jr JL, Rizzo JF (2000) Multi-electrode stimulation and recording in the isolated retina. J Neurosci Methods 101:31-42.

Guven D, Weiland JD, Fujii G, Mech BV, Mahadevappa M, Greenberg R, Roizenblatt R, Qiu G, Labree L, Wang X, Hinton D, Humayun MS (2005) Long-term stimulation by active epiretinal implants in normal and RCD1 dogs. J Neural Eng 2:S65-73.

Humayun MS (2003) Clinical trial results with a 16-electrode epiretinal implant in end-stage RP patients. In: The first DOE international symposium on artificial sight (Humayun MS, Greenbaum E, eds), Fort Lauderdale, FL: Department of Energy.

Humayun MS, Propst R, de Juan Jr E, McCormick K, Hickingbotham D (1994) Bipolar surface electrical stimulation of the vertebrate retina. Arch Ophthalmol 112:110-116.

Javaheri M, Hahn DS, Lakhanpal RR, Weiland JD, Humayun MS (2006) Retinal prostheses for the blind. Ann Acad Med Singapore 35:137-144.

Jensen RJ, Rizzo III JF (2007) Responses of ganglion cells to repetitive electrical stimulation of the retina. J Neural Eng 4:S1-S6.

Jensen RJ, Rizzo III JF, Ziv OR, Grumet A, Wyatt J (2003) Thresholds for activation of rabbit retinal ganglion cells with an ultrafine, extracellular microelectrode. Invest Ophthalmol Vis Sci 44:3533-3543.

Jensen RJ, Ziv OR, Rizzo JF (2005) Thresholds for activation of rabbit reti- 
nal ganglion cells with relatively large, extracellular microelectrodes. Invest Ophthalmol Vis Sci 46:1486-1496.

Johnson L, Perkins FK, O'Hearn T, Skeath P, Merritt C, Frieble J, Sadda S, Humayun M, Scribner D (2004) Electrical stimulation of isolated retina with microwire glass electrodes. J Neurosci Methods 137:265-273.

Jones BW, Marc RE (2005) Retinal remodeling during retinal degeneration. Exp Eye Res 81:123-137.

Jones BW, Watt CB, Frederick JM, Baehr W, Chen CK, Levine EM, Milam AH, Lavail MM, Marc RE (2003) Retinal remodeling triggered by photoreceptor degenerations. J Comp Neurol 464:1-16.

Katona SJ, Humayun MS, de Juan E, Suzuki S, Weiland JD, Greenberg R (1998) A comparison of electrical stimulation thresholds in normal versus degenerated (rd) mouse retina. Invest Ophthalmol Vis Sci 39:S991.

Kuras A, Baginskas A, Batuleviciene V (2004) Suprathreshold excitation of frog tectal neurons by short spike trains of single retinal ganglion cell. Exp Brain Res 159:509-518.

LeRoy C (1755) Où l'on rend compte de quelques tentatives que l'on a faites pour guérir plusieurs maladies par l'électricité. Hist Acad Roy Sciences (Paris), Mémoire Math Phys 60:87-95.

Litke AM (1998) The retinal readout system: an application of microstrip detector technology to neurobiology. Nucl Instrum Methods Phys Res A 418:203-209.

Litke AM, Chichilnisky EJ, Dabrowski W, Grillo AA, Grybos P, Kachiguine S, Rahman M, Taylor G (2003) Large-scale imaging of retinal output activity. Nucl Instrum Methods Phys Res A 501:298-307.

Litke AM, Bezayiff N, Chichilnisky EJ, Cunningham W, Dabrowski W, Grillo AA, Grivich M, Grybos P, Hottowy P, Kachiguine S, Kalmar RS, Mathieson K, Petrusca D, Rahman M, Sher A (2004) What does the eye tell the brain? Development of a system for the large scale recording of retinal output activity. IEEE Trans Nucl Sci 51:1434-1440.

Loewenstein JI, Montezuma SR, Rizzo III JF (2004) Outer retinal degeneration: an electronic retinal prosthesis as a treatment strategy. Arch Ophthalmol 122:587-596.

Mahadevappa M, Weiland JD, Yanai D, Fine I, Greenberg RJ, Humayun MS (2005) Perceptual thresholds and electrode impedance in three retinal prosthesis subjects. IEEE Trans Neural Syst Rehabil Eng 13:201-206.

Margalit E, Thoreson WB (2006) Inner retinal mechanisms engaged by retinal electrical stimulation. Invest Ophthalmol Vis Sci 47:2606-2612.

Mathieson K, Kachiguine S, Adams C, Cunningham W, Gunning D, O'Shea V, Smith KM, Chichilnisky EJ, Litke AM, Sher A, Rahman M (2004) Large-area microelectrode arrays for recording of neural signals. IEEE Trans Nucl Sci 51:2027-2031.

Merigan WH, Maunsell JH (1993) How parallel are the primate visual pathways? Annu Rev Neurosci 16:369-402.

Palanker DV, Vankov A, Huie P, Butterwick A, Chan I, Marmor MF, Blumenkranz MS (2007) High-resolution opto-electronic retinal prosthesis: physical limitations and design. In: Artificial sight; Springer series biological and medical physics/biomedical engineering (Humayun MS, Weiland JD, Chader G, Greenbaum E, eds), pp 255-277. New York: Springer.

Peichl L, Ott H, Boycott BB (1987) Alpha ganglion cells in mammalian retinae. Proc R Soc Lond B Biol Sci 231:169-197.

Rizzo JF, Miller S, Denison T, Herndon T, Wyatt JL (1996) Electricallyevoked cortical potentials from stimulation of rabbit retina with a microfabricated electrode array. Invest Ophthalmol Vis Sci [ARVO Abstr] 37:S707.

Rizzo JF, Wyatt J, Loewenstein J, Kelly S, Shire D (2003) Methods and perceptual thresholds for short-term electrical stimulation of human retina with microelectrode arrays. Invest Ophthalmol Vis Sci 44:5355-5361.
Rodieck RW (1998) The first steps in seeing. Sunderland, MA: Sinauer.

Rose TL, Robblee LS (1990) Electrical stimulation with Pt electrodes. VIII. Electrochemically safe charge injection limits with $0.2 \mathrm{~ms}$ pulses. IEEE Trans Biomed Eng 37:1118-1120.

Sanders CA, Nagler EJ, Zhou DM, Greenbaum D (2007) Dynamic interactions of retinal prosthesis electrodes with neural tissue and materials science in electrode design. In: Artificial sight (Humayun MS, Weiland JD, Chader G, Greenbaum E, eds), pp 209-226. New York: Springer.

Schiefer MA, Grill WM (2006) Sites of neuronal excitation by epiretinal electrical stimulation. IEEE Trans Neural Syst Rehabil Eng 14:5-13.

Sekirnjak C, Hottowy P, Sher A, Dabrowski W, Litke AM, Chichilnisky EJ (2006) Electrical stimulation of mammalian retinal ganglion cells with multielectrode arrays. J Neurophysiol 95:3311-3327.

Sekirnjak C, Hottowy P, Sher A, Dabrowski W, Litke AM, Chichilnisky EJ (2007) Electrical stimulation of mammalian retinal ganglion cells using dense arrays of small-diameter electrodes. In: Artificial sight (Humayun MS, Weiland JD, Chader G, Greenbaum E, eds), pp 333-345. New York: Springer.

Shah S, Hines A, Zhou D, Greenberg RJ, Humayun MS, Weiland JD (2007) Electrical properties of retinal-electrode interface. J Neural Eng 4:S24-S29.

Sterling P, Demb JB (2004) The synaptic organization of the brain. New York: Oxford UP.

Stett A, Barth W, Weiss S, Haemmerle H, Zrenner E (2000) Electrical multisite stimulation of the isolated chicken retina. Vision Res 40:1785-1795.

Suzuki S, Humayun MS, Weiland JD, Chen SJ, Margalit E, Piyathaisere DV, de Juan Jr E (2004) Comparison of electrical stimulation thresholds in normal and retinal degenerated mouse retina. Jpn J Ophthalmol 48:345-349.

Usrey WM, Reid RC (1999) Synchronous activity in the visual system. Annu Rev Physiol 61:435-456.

Uzzell VJ, Chichilnisky EJ (2004) Precision of spike trains in primate retinal ganglion cells. J Neurophysiol 92:780-789.

Van Essen DC (1985) Functional organization of primate visual cortex. In: Cerebral cortex (Peters AJ, Jones EG, eds), pp 259-2327. New York: Plenum.

Veraart C, Duret F, Brelen M, Oozeer M, Delbeke J (2004) Vision rehabilitation in the case of blindness. Expert Rev Med Devices 1:139-153.

Von der Malsburg, C (1994) The correlation theory of brain function. In: Models of neural networks II (Domany E, van Hemmen JL, Schulten K, eds), pp 95-119. Berlin: Springer.

Weiland JD, Liu W, Humayun MS (2005) Retinal prosthesis. Annu Rev Biomed Eng 7:361-401.

Wilms M, Eger M, Schanze T, Eckhorn R (2003) Visual resolution with epi-retinal electrical stimulation estimated from activation profiles in cat visual cortex. Vis Neurosci 20:543-555.

Wollner DA, Catterall WA (1986) Localization of sodium channels in axon hillocks and initial segments of retinal ganglion cells. Proc Natl Acad Sci USA 83:8424-8428.

Yanai D, Weiland JD, Mahadevappa M, Greenberg RJ, Fine I, Humayun MS (2007) Visual performance using a retinal prosthesis in three subjects with retinitis pigmentosa. Am J Ophthalmol 143:820-827.

Ye JH, Goo YS (2007) Comparison of voltage parameters for the stimulation of normal and degenerate retina. Conf Proc IEEE Eng Med Biol Soc 1:5782-5785.

Zrenner E (2002) Will retinal implants restore vision? Science 295:10221025. 